I have always felt that the role of the

BDJ should be inclined towards unbiased

reporting rather than influence...

\title{
Perchance to influence
}

On 4 November this year an early morning TV programme on the $\mathrm{BBC}$ reported a story linked to the Presidential election in the United States of America. Just before the election The Guardian newspaper in the UK urged its readers to write to the people in a crucial area of the state of Idaho suggesting that they vote for John Kerry, the democrat candidate, in order to help prevent the re-election of President George W. Bush. The initiative failed in its attempt (as we all now know) and in its report, the BBC highlighted the reaction of some of the US citizens to this intrusion into their affairs.

For me the most interesting comment came from Natasha Kaplinsky, one of the BBC presenters who was interviewing the features editor of The Guardian. She asked the editor if he felt that attempts to influence the election should be a journalist's role, or should it be to report on events in an unbiased way? His reply was that newspapers attempt to influence people all the time and that was how he saw his role, as an influencer rather than a pure reporter.

I must admit to feeling a sudden sense of sympathetic agreement with Natasha, and felt that perhaps in this, my last leader as editor of the $B D J$, I should clarify the position I took on this important debate as regards the editorial policy of the $B D J$. I have always felt that the role of the $B D J$ should be inclined towards unbiased reporting rather than influence. I know that this view is not held by all editors, as the past editor of the BMJ, Dr Richard Smith, told me that he saw the main role and objective of the $B M J$ as one of influence. I thought about this many times during my editorship, but always resisted all attempts to use the research papers, the news items and the clinical and educational articles in a political or promotional manner. I am sure I have not always succeeded as well as I would have liked, but that has been my editorial policy. For me factual reporting was more important than any attempt to influence.

Yet, if I am honest, I have to admit that the $B D J$ has occasionally taken a stance on certain matters such as fluoridation, the use of amalgam and smoking cessation. Here I have seen a role for a degree of influence and I have believed (backed up by the views of the editorial board and the many advisors to the $B D J$ ) that the evidence for our support is solid enough for the Journal to take a stand. Is this an attempt to influence? The answer is perhaps one of perception, depending on where you stand and what you believe. The world is never black and white.

The difference between my own policy and that of The Guardian (as I see it) is that the BDJ's stand has always been backed up the the current scientific evidence and it is here that the role of the Scientific Editor is so important. This importance, coupled with the fact this is my last BDJ as editor, is why I have published the lengthy opinion article on the role of the scientific editor in this issue. The article is a personal view from each of the five scientific editors to the $B D J$, and reflects not only their role and importance but acts as a guide for aspiring authors as well as a valuable historical record of the $B D J$ for the future. Sadly Frank Ashley, who occupied the post between Tony Naylor and John Murray, died in 2000 and thus could not be represented but I feel his work is still reflected in the words of the other editors before and after him.

And so my last editorial leader must draw to a close. Writing a leader twice a month for 12 and a half years (25 volumes and almost 300 issues) has been a joy and a challenge. Having the custodianship of the British Dental Journal has been a privilege and an honour. Working with virtually every facet of dentistry in the UK and abroad has been a delight and an education. I leave with a blend of sadness at the end of my time with the $B D J$ and anticipation for the future.

Mike Grace

Editor

m.grace@bda.org

doi: 10.1038/sj.bdj.4811895 